\title{
Monopoly and Contrived Depreciation
}

\section{Citation}

Barro, Robert J. 1972. Monopoly and contrived depreciation. Journal of Political Economy 80(3): 598-602.

\section{Published Version}

doi:10.1086/259909

\section{Permanent link}

http://nrs.harvard.edu/urn-3:HUL.InstRepos:3451394

\section{Terms of Use}

This article was downloaded from Harvard University's DASH repository, and is made available under the terms and conditions applicable to Other Posted Material, as set forth at http:// nrs.harvard.edu/urn-3:HUL.InstRepos:dash.current.terms-of-use\#LAA

\section{Share Your Story}

The Harvard community has made this article openly available.

Please share how this access benefits you. Submit a story.

Accessibility 


\title{
Monopoly and Contrived Depreciation
}

\author{
Robert J. Barro \\ Brown University and University of Chicago
}

It has often been argued that "artificial" limitations on durability ${ }^{1}$ tend to be associated with monopoly elements in an economy. A straightforward expression of this idea was given by Chamberlin (1957, p. 132): "The producer has to face the question of how durable to make his product. Evidently if he makes it too durable, as soon as people have bought one unit they will not need another for a substantial period during which there will be no repeat demand for his product. He has an interest then in making it less durable so that people will come back that much sooner to buy another unit."

On the other hand, since a monopolistic producer is being considered, it is not clear why increases in price cannot serve equally as well as reductions in durability. As a heuristic argument, if unit production costs do not diminish with decreased durability (the case considered here), costs of production would be lower when price, rather than durability, is the instrument for maximizing revenue (because lower replacement expenditure is involved). Therefore, at least to the extent that durability can be varied without affecting unit production costs, a profit-maximizing monopolist would choose the maximum durability. ${ }^{2}$

The above argument turns out to depend on an implicit assumption of perfect capital markets. In particular, the argument is valid if producers of durable goods employ the same discount rate for their profit flow that is used by owners of durables in discounting their flow of rental income. When the discount rate of owners is above that of producers, the owners are relatively more sensitive to shifts in price and relatively less sensitive

I am grateful for helpful comments from Peter Swan and from the referee. National Science Foundation grant GS-3246 supported this research.

${ }^{1}$ In this paper durability is assumed to be variable at zero cost up to some ceiling value. Therefore, the choice of any durability below the maximum constitutes what is referred to here as contrived depreciation. In the general case the choice of durability would take into account the cost of varying durability, and contrived depreciation could be measured as the gap from the durability chosen under perfect competition. Planned obsolescence is closely related to contrived depreciation, but this phenomenon is not treated explicitly in this paper.

2 This conclusion has been formally demonstrated by Swan (1970) in the context of a perfect capital market. He notes (p. 884): "The choice of durability by a monopolist is essentially one of minimizing the cost of the provision of any given service flow from a stock of durable goods." 
to shifts in durability. In this case some amount of reduced durability (contrived depreciation) may be consistent with a monopolist's maximization of profit, even when unit production costs are independent of durability.

The above arguments are established formally within the fairly simple framework discussed below.

\section{Household Behavior}

Households are assumed to be both the owners and the users of durables, with firms monopolizing the sale of durables to households. ${ }^{3}$ The utility of each household depends on the flow of consumables, $z$, and on the flow of services, $v$, from the single type of durable good. The stock of durables is denoted by $K$, and the service flow (per unit of time) is assumed to be proportional to the stock:

$$
v=\gamma K(\gamma>0) \text {. }
$$

Consumables have a price $p_{z}$, and durables, a price $p_{k}$. Both prices are regarded by consumers as constant over time. Household income is exogenous and constant and equal to $y$ dollars per unit of time. Durables are assumed to depreciate at the constant rate $\delta$. The discount rate applied by households to future cash flows is assumed to be constant and equal to $r_{h}$.

For simplicity, the utility function is assumed to be such that the representative household desires constant flows of consumables and durable services over time. ${ }^{4}$ If the household begins at time 0 without a stock of durables, it must initially purchase the stock amount, $k=v / \gamma$, in order to obtain the service flow, $v .^{5}$ Subsequently, the household purchases sufficient durables to maintain the stock at $k$. The flow purchase of durables subsequent to the initial stock purchase is, therefore,

$$
I=\delta K=\frac{\delta v}{\gamma} .
$$

${ }^{3}$ An alternative arrangement would have firms producing and owning durables and monopolizing the sale of services to households. A comparison of different ownership arrangements would be an interesting extension of the analysis.

+ If each household maximizes

$$
\int_{0}^{T} u(v, z) e^{-\rho t} d t
$$

where $\rho$ is the direct discount rate on utility and $T$ is the length of the planning horizon, constancy of $v$ and $z$ (for individual households) follows if $\rho=r_{h}$. However, constancy of $v$ and $z$ in the aggregate follows if the economy is in a steady state and does not require each individual to plan for constant $v$ and $z$ over time.

5 The model could be complicated to include an arbitrary initial stock of durables. However, it is crucial to consider the stock demand for durables as well as the flow (replacement) demand. A complete neglect of the stock demand led some previous authors into erroneous conclusions. 
At time 0 , the household makes a lump-sum purchase of the amount $p_{k}(v / \gamma)$. The flow of expenditure at all other times is that for replacement of durables, $p_{k} \delta(v / \gamma)$, plus the flow purchase of consumables, $p_{z} z$. The intertemporal budget constraint is, therefore (assuming a zero initial stock of wealth),

$$
p_{k} \frac{v}{\gamma}+\int_{0}^{\infty}\left(p_{k} \delta \frac{v}{\gamma}+p_{z} z\right) e^{-r_{h} t} d t=\int_{0}^{\infty} y e^{-r_{h} t} d t,
$$

or, simplifying,

$$
\frac{p_{k}}{\gamma}\left(r_{h}+\delta\right) v+p_{z} z=y .
$$

In equation (3), the price of durable services is effectively

$$
p_{v}=\frac{p_{k}}{\gamma}\left(r_{h}+\delta\right)
$$

The household chooses a flow of consumables and a flow of durable services to maximize utility, subject to its budget constraint. The formal optimization problem is: Max: $u(z, v)$; subject to equation (3). The demand function for durable services that emerges from this optimization can be written as

$$
v^{d}=v^{d}\left(\frac{p_{v}}{p_{z}}, \frac{y}{p_{z}}\right)
$$

where $p_{v}$ is indicated in equation (4). Equation (5) implies that the representative household's stock demand for durables is

$$
K^{d}=\frac{v^{d}}{\gamma}=\frac{1}{\gamma} v^{d}\left(\frac{p_{v}}{p_{z}}, \frac{y}{p_{z}}\right) \text {. }
$$

The (absolute) elasticity of demand for capital goods with respect to $p_{v} / p_{z}$ is

$$
\eta=-\frac{1}{K^{d}}\left[\frac{\partial K^{d}}{\partial\left(p_{v} / p_{z}\right)}\right] \frac{p_{v}}{p_{z}}>0 .
$$

The flow demand for durables subsequent to the initial purchase corresponds to the replacement necessary to maintain the stock at $K^{d}$ :

$$
I^{d}=\delta K^{d}=\frac{\delta}{\gamma} v^{d}\left(\frac{p_{v}}{p_{z}}, \frac{y}{p_{z}}\right) .
$$

The important property of the demand functions in equations (6) and (8) is the form in which $p_{k}, r_{h}$, and $\delta$ enter. In particular, $v^{d}$ (and there- 
fore $K^{d}$ ) depends only on the combination $p_{v}=\left(p_{k} / \gamma\right)\left(r_{h}+\delta\right)$. The flow demand, $I^{d}$, depends separately on $\delta$ as well as on $p_{v}$.

\section{Firm Behavior}

The durable goods producer is assumed to be a monopolist who is aware of the household demand functions in equations (6) and (8). For convenience, production of $K$ is assumed to take place at constant marginal cost, $c$ (see n. 7). The depreciation rate, $\delta$, of the durable is assumed to be a choice variable of the firm, subject to the constraint $\delta \supseteq \delta_{0} \supseteq 0$. In order to focus on the polar case of contrived depreciation, variations in $\delta$ (above some minimum, $\delta_{0}$ ) are assumed to have no effect on unit production costs. The question, then, is whether firms would ever choose a $\delta$ in excess of $\delta_{0}$, since this choice would amount to a pure case of socially uneconomic limitation on durability.

At the initial date, firms sell the stock of durables given by $K^{d}$ (eq. [6]). Subsequently, firms produce and sell according to $\delta K^{d}$ (eq. [8]). Assuming that firms choose a single pair of output price and depreciation rate, $\left(p_{k}, \delta\right)$, to apply for all time, and assuming the firm's discount rate to be $r_{f},{ }^{6}$ the firm's optimization problem (ignoring any fixed costs.) is

$$
\text { Max: } \pi=\left(p_{k}-c\right) K+\int_{0}^{\infty} \delta\left(p_{k}-c\right) K e^{-r_{f} t} d t,
$$

or, carrying out the integration,

$$
\operatorname{Max}: \pi=\left(p_{k}-c\right)\left(1+\frac{\delta}{r_{f}}\right) K,
$$

subject to equation (6): $K=K^{d}\left(p_{v} / p_{z}, y / p_{z}\right)$.

The first-order conditions for the maximization problem in equation (9), subject to $K=K^{d}$, may be expressed as: ${ }^{7}$

$$
\begin{gathered}
p_{k}^{*}=c\left(\frac{\eta}{\eta-1}\right) ; \\
\delta^{*}=r_{f}\left\{\frac{\left[\left(r_{h} / r_{f}\right)-\eta\right]}{\eta-1}\right\},
\end{gathered}
$$

${ }^{6}$ The discount rate of households, $r_{h}$, will tend to exceed that of firms because borrowing rates of individuals tend to exceed both individual lending rates and borrowing rates of firms. In this regard, see Hirshleifer (1958).

${ }^{7}$ If unit cost is a function of durability, $c=c(\delta), c^{\prime}(\delta) \leqslant 0$, the first-order maximization condition can be written as:

$$
\delta^{*}=\frac{r_{f}\left[r_{h} / r_{f}\right)-\eta}{\eta-1}-\frac{c^{\prime}(\delta)}{c(\delta)}\left(r_{f}+\delta\right)\left(r_{h}+\delta\right) .
$$

The condition $c^{\prime}(\delta)<0$ implies that $\delta^{*}$ will be above the level indicated in eq. (11). 
where $\eta$ is defined in equation (7).

Equation (10) yields a profit-maximizing price only if the monopolist is operating in the elastic region of the demand curve where $\eta>1$. The optimal value of $\delta$ is constrained according to $\delta \supseteq \delta_{0} \supseteq 0$. The solution indicated in equation (11) is positive when $\eta>1$ only if the demand elasticity is such that $\left(r_{h} / r_{f}\right)>\eta 1$. If $\left(r_{h} / r_{f}\right) \leqslant 1$ (and $\left.\eta>1\right)$, increases in $\delta$ invariably reduce $\pi$. Therefore, if the household discount rate is equal to or less than the firm's discount rate, the optimal value of $\delta$ is the constraint value, $\delta=\delta_{0}$, and contrived depreciation $\left(\delta>\delta_{0}\right)$ is non-optimal.

If $r_{h} / r_{f}$ is sufficiently above unity, $\delta^{*}$ in equation (11) will exceed $\delta_{0}$, and some amount of limited durability will characterize the profitmaximizing solution.

To summarize, the combination of monopoly with an imperfect capital market (where $r_{h}>r_{f}$ ) can lead to a rational (that is, profit-maximizing) basis for contrived depreciation. However, the existence of a perfect capital market $\left(r_{h}=r_{f}\right)$ precludes a rational basis for this type of limitation on durability, even in the presence of monopoly. ${ }^{8}$

\section{References}

Chamberlin, E. H. "The Product as an Economic Variable." In Towards a More General Theory of Value. New York: Oxford Univ. Press, 1957.

$\rightarrow$ Hirshleifer, J. "On the Theory of Optimal Investment Decisions." J.P.E. 66 (August 1958): 329-52.

$\rightarrow$ Levhari, D., and Srinivasan, T. N. "Durability of Consumption Goods: Competition versus Monopoly." A.E.R. 59 (March 1969): 102-7.

$\rightarrow$ Martin, D. D. "Monopoly Power and the Durability of Durable Goods." Southern Econ. J. 28 (January 1962): 271-77.

Swan, P. L. "Durability of Consumption Goods." A.E.R. 60 (December 1970) : 884-94.

8 This result accords with Swan's (1970) but differs from those obtained by Martin (1962) and by Levhari and Srinivasan (1969). The problem in Martin's model is that producer's revenue is derived solely from replacement sales, $\delta K$, and not from the initial stock sale, $K$. Hence, choosing $\delta=0(L=\infty$ in his notation in eq. [2], p. 272) leads to zero revenue, at least with a finite price, $p_{k}$. The problem in Levhari and Srinivasan is similar, as was pointed out by Swan (1970, p. 886). 